\title{
PEMODELAN PROSEDUR KARANTINA PENDATANG DALAM RANGKA PENCEGAHAN COVID-19 DI KOTA TARAKAN MENGGUNAKAN PETRI NET
}

\section{Modeling of Quarantine Procedure for Immigrant to Prevent the Covid-19 Transmission in Tarakan City using Petri Net}

\author{
Deny Murdianto ${ }^{1 *}$, Hadi Santoso ${ }^{2}$ \\ ${ }^{1,2}$ Prodi Teknik Mesin, Fakultas Teknik, Universitas Borneo Tarakan \\ Jl. Amal Lama No.1, Kota Tarakan, 77123, Indonesia \\ e-mail: 1*denymurdianto@gmail.com ; 2 hadisantoso.ubt@gmail.com \\ Corresponding author*
}

\begin{abstract}
Abstrak
Dalam rangka mencegah penularan Covid-19, pemerintah Kota Tarakan melakukan karantina terhadap pendatang yang masuk ke Kota Tarakan. Pemerintah Kota Tarakan telah membuat prosedur pelaksanaan karantina. Berdasarkan prosedur tersebut. Artikel ini bertujuan untuk membuat model prosedur karantina dengan menggunakan Petri net. Model Petri net dari prosedur karantina pendatang dalam rangka pencegahan Covid-19 di Kota Tarakan terdiri dari delapan belas transisi dan enam belas place. Evolusi keadaan ditunjukkan oleh matriks keadaan yang dianalisis terhadap prosedur karantina bagi pendatang dari dalam negeri dengan tujuan akhir Kota Tarakan. Penentuan marking harus ditentukan secara serius agar prosedur karantina ini dapat berjalan dengan lancar sesuai dengan tujuannya. Jumlah petugas harus benar-benar diperhitungkan agar tidak terjadi penumpukan antrian pendatang yang akan melakukan pemeriksaan. Kapasitas tempat karantina serta rumah sakit juga harus dipersiapkan dengan baik agar selalu tersedia dan siap menampung pendatang yang akan dikarantina.
\end{abstract}

Kata Kunci : petri net, karantina, covid-19.

\begin{abstract}
In ordered to prevent the transmission of Covid-19, the government of Tarakan city quarantines immigrants who entered Tarakan city. The government of Tarakan city have created a procedure for implementing the quarantine. Based on these procedures, this article aims to model the quarantine procedure using a Petri net. The Petri net model of the quarantine procedure for immigrants in the context of preventing Covid-19 in Tarakan City consists of eighteen transitions and sixteen places. The evolution of circumstances indicated by the matrix analyzed against the quarantine procedure for domestic immigrants with the final destination of Tarakan city. The determination of marking must be determined seriously so that this quarantine procedure can run smoothly according to purpose. The number of officers must be carefully taken into account so that there is no accumulation of queues of immigrants who was carry out the inspection. The capacity of quarantine places and hospitals must also be well prepared so that they are always available and ready to accept immigrants who was be quarantined.
\end{abstract}

Keywords: petri net, quarantine, covid-19. 


\section{PENDAHULUAN}

Indonesia terkena dampak buruk dari Covid-19 di mana tingkat kematiannya mencapai 8,9\% pada akhir Maret 2020. Ketidaksiapan layanan kesehatan dan langkah besar yang diambil oleh pemerintah mungkin dapat diubah untuk memberantas infeksi ini. Dianjurkan bagi Indonesia untuk memperketat himbauan untuk diam di rumah, menurunkan penyebaran penyakit dengan karantina wilayah dalam skala besar, meningkatkan pelayanan kesehatan, serta meningkatkan ketersediaan alat pelindung diri (APD). Penting bagi negara untuk menurunkan epidemic peak agar tidak membuat negara kewalahan dengan cara mengkarantina individu dengan riwayat kontak dengan kasus Covid-19. Karantina wilayah/ lockdown juga dapat meningkatkan doubling time epidemi secara signifikan [1].

Pembentukan aturan terkait pencegahan Covid-19 di Indonesia sangat penting dan mendesak untuk dilakukan dalam bentuk Peraturan Pemerintah dan Peraturan Menteri Kesehatan. Adapun salah satu Peraturan Pemerintah yang wajib dibentuk adalah tata cara pelaksanaan karantina wilayah di pintu masuk [2]. Karantina kesehatan merupakan sebuah peraturan yang telah diatur dalam undang-undang. Termaktub dan tercantum jelas bahwa karantina kesehatan sendiri merupakan cara yang efektif saat terjadi kedaruratan bencana seperti wabah yang dapat menimbulkan dampak dan kerugian besar bagi negara. UU Nomor 6 Tahun 2018 Tentang Kekarantinaan Kesehatan dengan jelas menerangkan tentang adanya pembatasan masuk-keluarnya individu ke suatu daerah yang telah dinyatakan sumber wabah, termasuk mengatur pula tentang adanya perintah untuk melakukan isolasi, karantina wilayah, vaksinasi dan lain sebagainya untuk menghentikan penyebaran wabah yang terjadi di Indonesia [3].

Pemerintah Kota Tarakan telah berusaha membuat aturan tentang karantina. Sebagai daerah transit di Provinsi Kalimantan Utara, Kota Tarakan membuat prosedur pemeriksaan bagi pendatang, baik bagi pendatang dengan tujuan Kota Tarakan, maupun bagi pendatang yang hanya transit di Kota Tarakan. Prosedur yang sudah dibuat tersebut harus dianalisa terlebih dahulu agar dalam pelaksanaannya dapat berjalan dengan baik. Analisis mengenai prosedur karantina terhadap pendatang yang masuk ke Kota Tarakan perlu dilakukan untuk memperkirakan sumber daya yang harus dipersiapkan. Jumlah petugas dan waktu pelayanan pemeriksaan serta jumlah fasilitas karantina merupakan beberapa variabel yang harus dipertimbangkan.

Jumlah sumber daya yang terbatas dan waktu pelayanan yang lama akan menimbulkan masalah antrian. Permasalahan antrian ini merupakan permasalahan sistem diskrit yang sering dijumpai. Antrian dapat terjadi pada sistem pelayanan kesehatan dan sistem lainnya. Beberapa peneliti menggunakan Petri net untuk memodelkan sistem, sistem produksi [4], automated manufacturing system [5], mesin pengering [6], sistem pembayaran tagihan listrik [7] dan sistem identifikasi sidik jari [8]. Selain itu, Petri net juga banyak digunakan untuk memodelkan sistem antrian layanan kesehatan, misalnya antrian klinik kesehatan [9], pelayanan farmasi [10], serta layanan rumah sakit [11]-[13]. Model antiran [12] memodelkan antrian yang terjadi pada pelayanan IGD rumah sakit dengan Petri net. Model Petri net dapat mensimulasikan sistem pelayanan IGD ke dalam bentuk diskrit. Model Petri net sistem pelayanan IGD RSUD Dr. Saiful Anwar Malang dibuat dengan menggunakan software PIPE dan direpresentasikan dalam matriks. Penelitian yang terkait dengan hal tersebut juga telah dilakukan [9], yaitu memodelkan antrian klinik kecantikan dengan petri net agar dapat diketahui alur dan sistemnya. Selanjutnya model tersebut direpresentasikan menggunakan matriks dan diaplikasikan dengan aljabar maxplus agar diperoleh model waktu tunggu antrian setiap pelayanan. Dengan mengetahui waktu antrian atau pelayanan diharapkan pengunjung maupun tenaga kerja klinik kecantikan dapat mengoptimalkan waktu antrian.

Berdasarkan prosedur karantina yang telah dibuat oleh Pemerintah Kota Tarakan dan analisis masalah antrian yang mungkin terjadi dalam prosedur karantina tersebut, pada artikel ini kami akan membuat model Petri net prosedur karantina, melakukan analisis sederhana mengenai dinamika Petri net yang dibangun, serta menganalisis evolusi keadaan dengan menggunakan matriks backward dan forward accident.

\section{METODE PENELITIAN}

Penelitian ini bertujuan memodelkan prosedur karantina pendatang dalam rangka pencegahan Covid19 di Kota Tarakan dengan menggunakan Petri net. Penelitian ini dapat dibagi menjadi beberapa tahap sebagai berikut:

1) Mengamati prosedur pelayanan karantina pendatang dalam rangka pencegahan Covid-19 di Kota Tarakan.

2) Membangun Petri net sesuai dengan prosedur karantina. 
3) Menganalisa keadaan awal dan dinamika Petri net.

4) Menganalisa Petri net sesuai dengan prosedur karantina untuk pendatang dari dalam negeri dengan tujuan akhir Kota Tarakan.

5) Merepresentasikan Petri net dengan menggunakan matriks incidence dan melakukan simulasi evolusi keadaan.

Pada penelitian ini diasumsikan masing-masing petugas hanya satu di setiap pos pemeriksaan. Begitu juga dengan tempat karantina yang tersedia. Selanjutnya, kami akan menjelasan mengenai prosedur karantina dan Petri net yang dimaksud dalam artikel ini.

\subsection{Prosedur Karantina Pendatang di Kota Tarakan}

Pada bagian ini kami akan menjelaskan prosedur karantina yang dilaksanakan Pemerintah Kota Tarakan. Pendatang yang dimaksud dalam hal ini adalah penumpang dari bandar udara internasional Juwata, pelabuhan Ferry, pelabuhan rakyat, dan pelabuhan Malundung di Kota Tarakan. Pada tahap awal, semua penumpang akan dijemput menggunakan bus menuju tempat screening kesehatan. Selanjutnya seluruh penumpang diberi gelang penanda, dilakukan pemeriksaaan, dan dilakukan pemisahan berdasarkan asal kedatangan, tujuan akhir, institusi penanggungjawab, faktor resiko, dan status kesehatan. Tindakan selanjutnya dibedakan berdasarkan asal penumpang, yaitu yang berasal dari dalam negeri dan dari luar negeri. Bagi penumpang dari dalam negeri adalah sebagai berikut:

1. Penumpang tujuan kabupaten dalam Kalimantan Utara

- hasil pemeriksaan sehat dan sakit ringan akan dikarantina selama satu hari kemudian diantar ke pelabuhan speedboat dan melanjutkan karantina di kabupaten tujuan

- hasil pemeriksaan sakit sedang dan sakit berat akan dirujuk ke RSU Kota Tarakan atau RSUD Tarakan

2. Penumpang tujuan tarakan dengan jaminan institusi

- hasil pemeriksaan sehat dan sakit ringan akan dikarantina selama satu hari kemudian diserahkan ke institusi penjamin untuk melanjutkan karantina selama empat belas hari

- hasil pemeriksaan sakit sedang dan sakit berat akan dirujuk ke RSU Kota Tarakan atau RSUD Tarakan

3. Penumpang umum tujuan Tarakan tanpa jaminan institusi

- hasil pemeriksaan sehat akan dikarantina selama satu hari kemudian diserahkan kepada ketua RT domisili penumpang yang bersangkutan untuk melanjutkan isolasi mandiri di rumah selama empat belas hari

- $\quad$ hasil pemeriksaan sakit ringan dan sakit sedang akan dirawat selama dua sampai empat belas hari di rumah sakit darurat/ lapangan, rumah sakit angkatan laut, atau RSU Kota Tarakan

- Hasil pemeriksaan sakit berat akan dirujuk ke RSUD Tarakan

Bagi penumpang dari luar negeri:

1. Kondisi sehat, sakit ringan, dan sakit sedang akan dikarantina selama tujuh hari dan dilakukan rapid diagnostic test $(\mathrm{rdt})$ covid-19

a. Jika hasil rdt negatif akan diserahkan ke institusi penjamin/ ketua RT untuk melanjutkan karantina mandiri hingga empat belas hari

b. Jika hasil rdt positif akan dilakukan tes swab

- Jika hasil negatif akan diserahkan ke institusi penjamin/ ketua RT untuk melanjutkan karantina mandiri hingga empat belas hari

- Jika hasil positif perawatan akan dilanjutkan

2. Kondisi sakit berat akan dirujuk ke RSUD Tarakan

\subsection{Petri Net}

Petri net merupakan himpunan place dan transisi yang digunakan untuk menggambarkan keadaan atau kejadian diskrit. Antara place dan transisi dihubungkan dengan arcs berarah yang memiliki bobot $w$. Pada Petri net bertanda, marking terdapat pada place yang dapat berpindah apabila suatu transisi difire. Apabila suatu kejadian bersyarat atau membutuhkan sumber daya, maka syarat atau sumber daya tersebut harus terpenuhi terlebih dahulu agar suatu transisi bisa difire dan marking berpindah dari satu place ke place yang lainnya. 
Petri net bertanda (marked) adalah 5-tuple $\left(P, T, A, w, \boldsymbol{x}_{0}\right)$ dimana $(P, T, A, w)$ adalah Petri net dan $\boldsymbol{x}_{0}$ adalah marking/ keadaan awal [14].

- $P=\left\{p_{1}, p_{2}, \ldots, p_{n}\right\}$ adalah himpunan berhingga dari place,

- $T=\left\{t_{1}, t_{2}, \ldots, t_{m}\right\}$ adalah himpunan berhingga dari transisi,

- $A \subseteq(P \times T) \cup(T \times P)$ adalah himpunan dari garis berarah (arcs),

- $w: A \rightarrow\{1,2,3, \ldots\}$ adalah fungsi bobot,

- $\boldsymbol{x}_{0}: P \rightarrow\{0,1,2,3, \ldots\}$ marking awal, dimana $P \cap T=\emptyset \operatorname{dan} P \cup T \neq \emptyset$.

Keadaan (state) Petri net bertanda adalah $\boldsymbol{x}=\left[x\left(p_{1}\right), x\left(p_{2}\right), \ldots, x\left(p_{n}\right)\right]^{T}$. Transisi $t_{j} \in T$ dalam Petri net bertanda dikatakan enable jika $x\left(p_{i}\right) \geq w\left(p_{i}, t_{j}\right), \forall p_{i} \in I\left(t_{j}\right)$. Selanjutnya, matriks backward (forward) incidence yang merepresentasikan Petri net adalah matriks berukuran $n \times m$ dengan elemen baris ke- $i$ kolom ke- $j$ adalah $A_{b}(i, j) \stackrel{\text { def }}{=} w\left(p_{i}, t_{j}\right)\left(A_{f}(i, j) \stackrel{\text { def }}{=} w\left(t_{j}, p_{i}\right)\right)$. Salah satu kegunaan matriks backward incidence adalah menentukan transisi yang enable [15].

\section{HASIL DAN PEMBAHASAN}

Sebelum membangun model Petri net dari prosedur karantina di atas, ada beberapa hal yang perlu diperhatikan. Dalam prosedur tersebut, untuk penumpang dengan tujuan akhir kabupaten dalam Provinsi Kalimantan Utara dan penumpang dengan institusi penjamin memiliki urutan langkah penanganan yang sama, yaitu untuk penumpang sehat dan sakit ringan akan dikarantina selama satu hari kemudian diantarkan untuk perjalanan selanjutnya atau diserahkan kepada institusi penjamin. Sedangkan untuk penumpang yang sakit sedang dan sakit berat akan langsung dirujuk ke rumah sakit. Berdasarkan prosedur karantina yang dijelaskan pada bagian sebelumnya dan juga beberapa asumsi di atas, kami membangun model Petri net sebagai berikut.



Gambar 1. Petri net prosedur karantina pendatang di Kota Tarakan 
Tabel 1. Keterangan transisi

\begin{tabular}{ll}
\hline Transisi & Keterangan \\
\hline Datang & Penumpang datang \\
\hline Mln & Mulai cek kesehatan (penumpang luar negeri) \\
\hline Mdn & Mulai cek kesehatan (penumpang tujuan kabupaten di kaltara dan instansi) \\
\hline Mt & Mulai cek kesehatan (penumpang tujuan tarakan) \\
\hline s/sr/ss_ln & Sehat/ sakit ringan/ sakit sedang (penumpang luar negeri) \\
\hline sb_ln & Sakit berat penumpang luar negeri \\
\hline s/sr_dn & Sehat/ sakit ringan penumpang tujuan kabupaten di kaltara dan instansi \\
\hline Ss/sb_dn & Sakit sedang/ sakit berat penumpang tujuan kabupaten di kaltara dan instansi \\
\hline s_t & Sehat penumpang tarakan \\
\hline sr/ss_t & Sakit ringan/ sakit sedang penumpang tarakan \\
\hline sb_t & Sakit berat penumpang tarakan \\
\hline rdt- & Rapid tes negatif \\
\hline rdt+ & Rapid tes positif \\
\hline sk1 & Selesai karantina 1 hari \\
\hline sk2 & Selesai karantina 2 - 14 hari \\
\hline swab- & Swab tes negatif \\
\hline swab+ & Swab tes positif \\
\hline Srs & Selesai/ keluar rumah sakit \\
\hline
\end{tabular}

Tabel 2. Keterangan place

\begin{tabular}{ll}
\hline Place & Keterangan \\
\hline antri & Penumpang antri untuk cek kesehatan \\
\hline iln & Idle cek penumpang luar negeri \\
\hline idn & Idle cek penumpang tujuan kabupaten di kaltara dan instansi \\
\hline ict & Idle cek penumpang tujuan Tarakan \\
\hline cln & Cek penumpang luar negeri \\
\hline cdn & Cek penumpang tujuan kabupaten di kaltara dan instansi \\
\hline $\mathrm{ct}$ & Cek penumpang tujuan Tarakan \\
\hline $\mathrm{ik} 7$ & Idle karantina 7 hari \\
\hline $\mathrm{k} 7$ & Penumpang karantina tujuh hari \\
\hline $\mathrm{ik} 1$ & Idle karantina 1 hari \\
\hline $\mathrm{k} 1$ & Penumpang karantina 1 hari \\
\hline $\mathrm{k} 2$ & Idle karantina 2 - 14 hari \\
\hline $\mathrm{k} 2$ & Penumpang karantina 2 - 14 hari \\
\hline $\mathrm{irs}$ & Penumpang swab tes \\
\hline $\mathrm{rs}$ & Idle rumah sakit \\
\hline
\end{tabular}

Petri net terdiri dari delapan belas transisi dan enam belas place. Pada keadaan awal terdapat token di place iln, idn, ict, ik7, ik1, ik2, dan irs. Token di place iln, idn, dan ict menyatakan bahwa petugas pemeriksaan siap melakukan pemeriksaan kepada pendatang. Token di place ik7, ik1, ik2, dan irs menyatakan bahwa tempat karantina dan rumah sakit tersedia bagi pendatang. Pada kajian ini, masing-masing place tersebut diasumsikan hanya memiliki satu token.

Transisi awal, yaitu transisi datang akan selalu enable. Pemfirean transisi ini akan mengakibatkan penambahan token di place antri. Apabila terus terjadi pemfirean, maka akan terjadi penumpukan token atau jumlah pendatang yang antri untuk dilakukan pemeriksaan awal. Misal pada keadaan awal transisi datang difire, maka akan terdapat token di place antri. Pada keadaan ini, ada empat transisi yang menjadi enable, yaitu transisi datang, mln, mdn, dan mt. Transisi datang, seperti yang sudah dibahas sebelumnya, akan selalu enable. Sedangkan untuk tiga transisi lainnya, selain karena dipengaruhi place antri, juga dipengaruhi oleh place iln untuk transisi mln, place idn untuk transisi mdn, dan place ict untuk transisi mt. Place iln, idn, dan ict merupakan jumlah petugas yang siap melakukan pemeriksaan awal. Jumlah token yang merepresentasikan jumlah petugas ini harus diupayakan selalu tersedia agar semua penumpang datang bisa selalu atau segera diperiksa dan tidak terjadi penumpukan antrian.

Selanjutnya analisis akan dilakukan terhadap prosedur karantina bagi pendatang dari dalam negeri dengan tujuan akhir Kota Tarakan. Petri net terdiri dari delapan transisi dan sembilan place. 


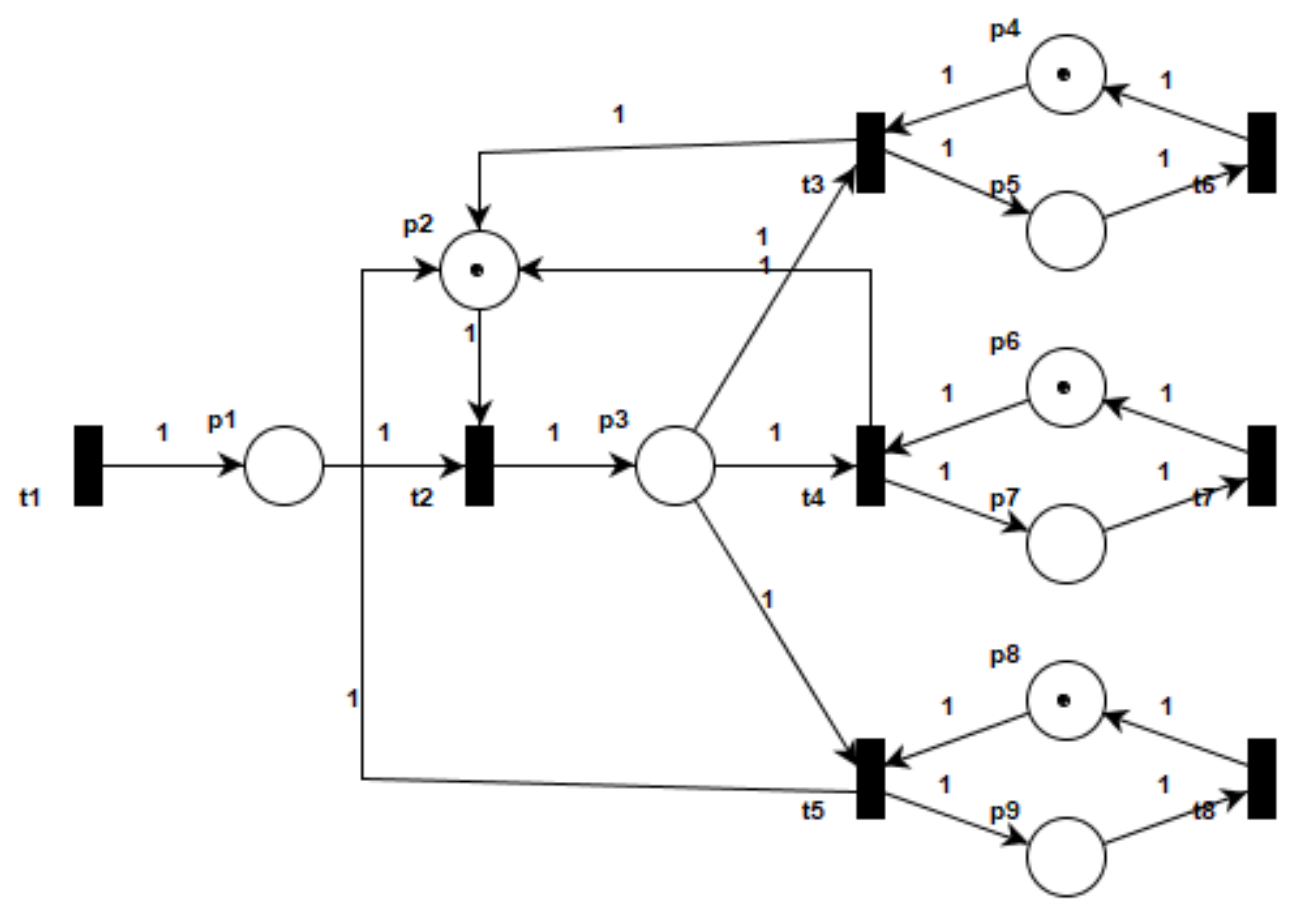

Gambar 2. Petri net prosedur karantina pendatang dari dalam negeri dengan tujuan akhir Kota Tarakan

$t_{1}$ : pendatang tiba di Kota Tarakan

$t_{2}$ : pendatang mulai cek kesehatan

$t_{3}:$ pendatang sehat

$t_{4}$ : pendatang sakit ringan/ sakit sedang

$t_{5}:$ pendatang sakit berat

$t_{6}$ : pendatang selesai karantina 1 hari

$t_{7}$ : pendatang selesai karantina 2-14 hari

$t_{8}:$ pendatang selesai/ keluar rs

$$
\begin{aligned}
& p_{1}: \text { pendatang antri } \\
& p_{2}: \text { idle petugas cek kesehatan } \\
& p_{3}: \text { pendatang cek kesehatan } \\
& p_{4}: \text { idle karantina } 1 \text { hari } \\
& p_{5}: \text { karantina } 1 \text { hari } \\
& p_{6}: \text { idle karantina } 2-14 \text { hari } \\
& p_{7}: \text { karantina } 2-14 \text { hari } \\
& p_{8}: \text { idle rumah sakit } \\
& p_{9}: \text { rumah sakit }
\end{aligned}
$$

Representasi matriks dari petri net di gambar tersebut adalah matriks dengan ukuran 9 (place) $\times 8$ (transisi), yaitu matriks backward incidence dan matriks forward incidence serta matriks $A$ yang merupakan matriks combined incidence atau matriks incidence. Keadaan awal ditujukkan oleh matriks $\boldsymbol{x}_{0}$. Evolusi keadaan diperoleh dengan cara melakukan pemfirean transisi yang enable secara bergantian sehingga diperoleh evolusi keadaan hingga kembali lagi kepada keadaan awal.

$$
\begin{gathered}
A_{b}=\left[\begin{array}{cccccccc}
0 & 1 & 0 & 0 & 0 & 0 & 0 & 0 \\
0 & 1 & 0 & 0 & 0 & 0 & 0 & 0 \\
0 & 0 & 1 & 1 & 1 & 0 & 0 & 0 \\
0 & 0 & 1 & 0 & 0 & 0 & 0 & 0 \\
0 & 0 & 0 & 0 & 0 & 1 & 0 & 0 \\
0 & 0 & 0 & 1 & 0 & 0 & 0 & 0 \\
0 & 0 & 0 & 0 & 0 & 0 & 1 & 0 \\
0 & 0 & 0 & 0 & 1 & 0 & 0 & 0 \\
0 & 0 & 0 & 0 & 0 & 0 & 0 & 1
\end{array}\right] \quad A_{f}=\left[\begin{array}{ccccccccc}
1 & 0 & 0 & 0 & 0 & 0 & 0 & 0 \\
0 & 0 & 1 & 1 & 1 & 0 & 0 & 0 \\
0 & 1 & 0 & 0 & 0 & 0 & 0 & 0 \\
0 & 0 & 0 & 0 & 0 & 1 & 0 & 0 \\
0 & 0 & 1 & 0 & 0 & 0 & 0 & 0 \\
0 & 0 & 0 & 0 & 0 & 0 & 1 & 0 \\
0 & 0 & 0 & 1 & 0 & 0 & 0 & 0 \\
0 & 0 & 0 & 0 & 0 & 0 & 0 & 1 \\
0 & 0 & 0 & 0 & 1 & 0 & 0 & 0
\end{array}\right] \\
A=A_{f}-A_{b}
\end{gathered}
$$


Keadaan awal petri net adalah $\boldsymbol{x}_{0}=\left[\begin{array}{lllllllll}0 & 1 & 0 & 1 & 0 & 1 & 0 & 1 & 0\end{array}\right]^{T}$. Transisi $t_{1}$ enable karena $\boldsymbol{x}_{0} \geq$ $A_{b}(:, 1)$. Dengan memfire $t_{1}$, maka keadaan berikutnya adalah

$\boldsymbol{x}_{1}=\boldsymbol{x}_{0}+A \boldsymbol{e}_{1}=\left[\begin{array}{l}0 \\ 1 \\ 0 \\ 1 \\ 0 \\ 1 \\ 0 \\ 1 \\ 0\end{array}\right]+\left[\begin{array}{cccccccc}1 & -1 & 0 & 0 & 0 & 0 & 0 & 0 \\ 0 & -1 & 1 & 1 & 1 & 0 & 0 & 0 \\ 0 & 1 & -1 & -1 & -1 & 0 & 0 & 0 \\ 0 & 0 & -1 & 0 & 0 & 1 & 0 & 0 \\ 0 & 0 & 1 & 0 & 0 & -1 & 0 & 0 \\ 0 & 0 & 0 & -1 & 0 & 0 & 1 & 0 \\ 0 & 0 & 0 & 1 & 0 & 0 & -1 & 0 \\ 0 & 0 & 0 & 0 & -1 & 0 & 0 & 1 \\ 0 & 0 & 0 & 0 & 1 & 0 & 0 & -1\end{array}\right]\left[\begin{array}{l}1 \\ 0 \\ 0 \\ 0 \\ 0 \\ 0 \\ 0 \\ 0\end{array}\right]$

$\boldsymbol{x}_{1}=\boldsymbol{x}_{0}+A \boldsymbol{e}_{1}=\left[\begin{array}{l}0 \\ 1 \\ 0 \\ 1 \\ 0 \\ 1 \\ 0 \\ 1 \\ 0\end{array}\right]+\left[\begin{array}{l}1 \\ 0 \\ 0 \\ 0 \\ 0 \\ 0 \\ 0 \\ 0 \\ 0\end{array}\right]=\left[\begin{array}{l}1 \\ 1 \\ 0 \\ 1 \\ 0 \\ 1 \\ 0 \\ 1 \\ 0\end{array}\right]$

Pada keadaan $\boldsymbol{x}_{1}$, terdapat token di place $p_{1}$ yang berarti terdapat pendatang yang sedang antri. Karena $\boldsymbol{x}_{1}=$ $\left[\begin{array}{lllllllll}1 & 1 & 0 & 1 & 0 & 1 & 0 & 1 & 0\end{array}\right]^{T}$, maka selain transisi $t_{1}$ yang selalu enable, transisi $t_{2}$ juga enable karena $\boldsymbol{x}_{1} \geq A_{b}(:, 2)$. Dengan memfire $t_{2}$, maka keadaan berikutnya adalah

$\boldsymbol{x}_{2}=\boldsymbol{x}_{1}+A \boldsymbol{e}_{2}=\left[\begin{array}{l}1 \\ 1 \\ 0 \\ 1 \\ 0 \\ 1 \\ 0 \\ 1 \\ 0\end{array}\right]+\left[\begin{array}{cccccccc}1 & -1 & 0 & 0 & 0 & 0 & 0 & 0 \\ 0 & -1 & 1 & 1 & 1 & 0 & 0 & 0 \\ 0 & 1 & -1 & -1 & -1 & 0 & 0 & 0 \\ 0 & 0 & -1 & 0 & 0 & 1 & 0 & 0 \\ 0 & 0 & 1 & 0 & 0 & -1 & 0 & 0 \\ 0 & 0 & 0 & -1 & 0 & 0 & 1 & 0 \\ 0 & 0 & 0 & 1 & 0 & 0 & -1 & 0 \\ 0 & 0 & 0 & 0 & -1 & 0 & 0 & 1 \\ 0 & 0 & 0 & 0 & 1 & 0 & 0 & -1\end{array}\right]\left[\begin{array}{l}0 \\ 1 \\ 0 \\ 0 \\ 0 \\ 0 \\ 0 \\ 0\end{array}\right]$

$\boldsymbol{x}_{2}=\boldsymbol{x}_{1}+A \boldsymbol{e}_{2}=\left[\begin{array}{l}1 \\ 1 \\ 0 \\ 1 \\ 0 \\ 1 \\ 0 \\ 1 \\ 0\end{array}\right]+\left[\begin{array}{c}-1 \\ -1 \\ 1 \\ 0 \\ 0 \\ 0 \\ 0 \\ 0 \\ 0\end{array}\right]=\left[\begin{array}{l}0 \\ 0 \\ 1 \\ 1 \\ 0 \\ 1 \\ 0 \\ 1 \\ 0\end{array}\right]$

Pada keadaan $\boldsymbol{x}_{2}$, terdapat token di place $p_{3}$ yang berarti pendatang sedang di cek kesehatannya oleh petugas. Sehingga transisi $t_{2}$ menjadi tidak enable. Karena $\boldsymbol{x}_{2}=\left[\begin{array}{lllllllll}0 & 0 & 1 & 1 & 0 & 1 & 0 & 1 & 0\end{array}\right]^{T}$, maka selain transisi $t_{1}$ yang selalu enable, transisi $t_{3}, t_{4}$, dan $t_{5}$ menjadi enable karena $\boldsymbol{x}_{2} \geq A_{b}(:, j)$ untuk $j=3,4,5$.

Misal transisi $t_{3}$ difire, maka

$$
\boldsymbol{x}_{3}=\boldsymbol{x}_{2}+A \boldsymbol{e}_{3}=\left[\begin{array}{l}
0 \\
0 \\
1 \\
1 \\
0 \\
1 \\
0 \\
1 \\
0
\end{array}\right]+\left[\begin{array}{cccccccc}
1 & -1 & 0 & 0 & 0 & 0 & 0 & 0 \\
0 & -1 & 1 & 1 & 1 & 0 & 0 & 0 \\
0 & 1 & -1 & -1 & -1 & 0 & 0 & 0 \\
0 & 0 & -1 & 0 & 0 & 1 & 0 & 0 \\
0 & 0 & 1 & 0 & 0 & -1 & 0 & 0 \\
0 & 0 & 0 & -1 & 0 & 0 & 1 & 0 \\
0 & 0 & 0 & 1 & 0 & 0 & -1 & 0 \\
0 & 0 & 0 & 0 & -1 & 0 & 0 & 1 \\
0 & 0 & 0 & 0 & 1 & 0 & 0 & -1
\end{array}\right]\left[\begin{array}{l}
0 \\
0 \\
1 \\
0 \\
0 \\
0 \\
0 \\
0
\end{array}\right]
$$


$\boldsymbol{x}_{3}=\boldsymbol{x}_{2}+A \boldsymbol{e}_{3}=\left[\begin{array}{l}0 \\ 0 \\ 1 \\ 1 \\ 0 \\ 1 \\ 0 \\ 1 \\ 0\end{array}\right]+\left[\begin{array}{c}0 \\ 1 \\ -1 \\ -1 \\ 1 \\ 0 \\ 0 \\ 0 \\ 0\end{array}\right]=\left[\begin{array}{l}0 \\ 1 \\ 0 \\ 0 \\ 1 \\ 1 \\ 0 \\ 1 \\ 0\end{array}\right]$

Pada keadaan $\boldsymbol{x}_{3}$, terdapat token di place $p_{5}$ yang berarti pendatang sedang melakukan karantina selama satu hari. Karena $\boldsymbol{x}_{3}=\left[\begin{array}{llllllllll}0 & 1 & 0 & 0 & 1 & 1 & 0 & 1 & 0\end{array}\right]^{T}$ maka selain transisi $t_{1}$ yang selalu enable, transisi $t_{6}$ juga menjadi enable karena $\boldsymbol{x}_{2} \geq A_{b}(:, 6)$. Apabila transisi $t_{6}$ difire maka

$\boldsymbol{x}_{4}=\boldsymbol{x}_{3}+A \boldsymbol{e}_{6}=\left[\begin{array}{l}0 \\ 1 \\ 0 \\ 0 \\ 1 \\ 1 \\ 0 \\ 1 \\ 0\end{array}\right]+\left[\begin{array}{cccccccc}1 & -1 & 0 & 0 & 0 & 0 & 0 & 0 \\ 0 & -1 & 1 & 1 & 1 & 0 & 0 & 0 \\ 0 & 1 & -1 & -1 & -1 & 0 & 0 & 0 \\ 0 & 0 & -1 & 0 & 0 & 1 & 0 & 0 \\ 0 & 0 & 1 & 0 & 0 & -1 & 0 & 0 \\ 0 & 0 & 0 & -1 & 0 & 0 & 1 & 0 \\ 0 & 0 & 0 & 1 & 0 & 0 & -1 & 0 \\ 0 & 0 & 0 & 0 & -1 & 0 & 0 & 1 \\ 0 & 0 & 0 & 0 & 1 & 0 & 0 & -1\end{array}\right]\left[\begin{array}{l}0 \\ 0 \\ 0 \\ 0 \\ 0 \\ 1 \\ 0 \\ 0\end{array}\right]$

$\boldsymbol{x}_{4}=\boldsymbol{x}_{3}+A \boldsymbol{e}_{6}=\left[\begin{array}{l}0 \\ 1 \\ 0 \\ 0 \\ 1 \\ 1 \\ 0 \\ 1 \\ 0\end{array}\right]+\left[\begin{array}{c}0 \\ 0 \\ 0 \\ 1 \\ -1 \\ 0 \\ 0 \\ 0 \\ 0\end{array}\right]=\left[\begin{array}{l}0 \\ 1 \\ 0 \\ 1 \\ 0 \\ 1 \\ 0 \\ 1 \\ 0\end{array}\right]=x_{0}$

Setelah dilakukan pemfirean transisi $t_{6}$, kita akan mendapatkan keadaan seperti keadaan awal. Keadaan awal juga bisa kita peroleh dengan cara lain, yaitu saat keadaan $\boldsymbol{x}_{2}$ dicapai ada tiga transisi yang bisa difire. Urutan pemfirean yang mungkin untuk kembali ke keadaan awal tersebut adalah sebagai berikut:

1)

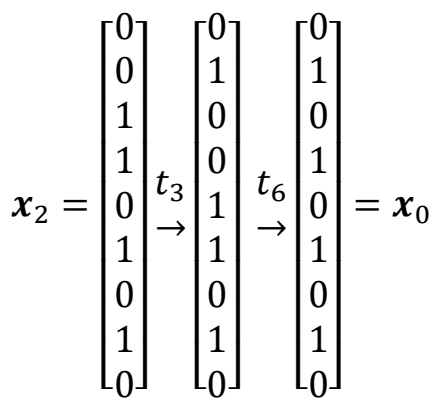

(pendatang sehat, karantina satu hari, dan selesai karantina satu hari)

2) $\boldsymbol{x}_{2}=\left[\begin{array}{l}0 \\ 0 \\ 1 \\ 1 \\ 0 \\ 1 \\ 0 \\ 1 \\ 0\end{array}\right] \rightarrow\left[\begin{array}{l}0 \\ 1 \\ 0 \\ t_{4} \\ 1 \\ 0 \\ 0 \\ 1 \\ 1 \\ 0\end{array}\right] \rightarrow\left[\begin{array}{l}t_{7} \\ \rightarrow \\ 1 \\ 0 \\ 1 \\ 0 \\ 0 \\ 1 \\ 0\end{array}\right]=\boldsymbol{x}_{0}$

(pendatang sakit ringan/ sakit sedang, karantina dua sampai empat belas hari, dan selesai karantina dua sampai empat belas hari) 
3) $\boldsymbol{x}_{2}=\left[\begin{array}{l}0 \\ 0 \\ 1 \\ 1 \\ 0 \\ 1 \\ 0 \\ 1 \\ 0\end{array}\right] \rightarrow\left[\begin{array}{l}0 \\ 1 \\ 0 \\ 1 \\ 0 \\ 1 \\ 0 \\ 0 \\ 1\end{array}\right] \rightarrow\left[\begin{array}{l}0 \\ 1 \\ 0 \\ 1 \\ 0 \\ 1 \\ 0 \\ 1 \\ 0\end{array}\right]=x_{0}$

(pendatang sakit berat, dirawat di rumah sakit, dan pendatang sehat/ keluar dari rumah sakit)

\section{KESIMPULAN}

Berdasarkan analisis model petri net dari prosedur karantina pendatang dalam rangka pencegahan Covid-19 di Kota Tarakan diperoleh kesimpulan sebagai berikut:

1. Petri net terdiri dari delapan belas transisi dan enam belas place.

2. Pada keadaan awal token di place iln, idn, dan ict menyatakan bahwa petugas pemeriksaan siap melakukan pemeriksaan kepada pendatang. Sedangkan token di place ik7, ik1, ik2, dan irs menyatakan bahwa tempat karantina dan rumah sakit tersedia bagi pendatang.

3. Pada kajian ini, masing-masing place tersebut diasumsikan hanya memiliki satu token. Pada kenyataannya penentuan token ini harus ditentukan secara serius agar prosedur karantina ini dapat berjalan dengan lancar sesuai dengan tujuannya. Jumlah petugas harus benar-benar diperhitungkan agar tidak terjadi penumpukan antrian pendatang yang akan melakukan pemeriksaan. Kapasitas tempat karantina serta rumah sakit juga harus dipersiapkan dengan baik agar selalu tersedia dan siap menampung pendatang yang akan dikarantina.

4. Evolusi keadaan ditunjukkan oleh matriks keadaan yang dianalisis terhadap prosedur karantina bagi pendatang dari dalam negeri dengan tujuan akhir Kota Tarakan. Petri net terdiri dari delapan transisi dan sembilan place.

5. Terdapat tiga cara untuk dapat kembali kepada keadaan awal, yaitu $\boldsymbol{x}_{0} \rightarrow t_{1}, t_{2}, t_{3}, t_{6} \rightarrow \boldsymbol{x}_{0} ; \boldsymbol{x}_{0} \rightarrow t_{1}$, $t_{2}, t_{4}, t_{7} \rightarrow \boldsymbol{x}_{0}$; dan $\boldsymbol{x}_{0} \rightarrow t_{1}, t_{2}, t_{5}, t_{8} \rightarrow \boldsymbol{x}_{0}$.

6. Perlu dilakukan penelitian lanjutan untuk dapat memperkirakan waktu yang digunakan pada setiap tahapan karantina agar dapat menentukan sumber daya dengan tepat, yaitu terkait jumlah petugas dan jumlah fasilitas yang harus disediakan.

\section{UCAPAN TERIMA KASIH}

Ucapan terima kasih disampaikan kepada semua pihak yang telah membantu penulis dalam mengerjakan penelitian ini. Serta kepada Jurusan Teknik Mesin, Fakutas Teknik, Universitas Borneo Tarakan atas kesempatan dan dukungan menyelesaikan penelitian ini.

\section{DAFTAR PUSTAKA}

[1] S. Setiati and M. K. Azwar, "COVID-19 and Indonesia," Acta Med Indones - Indones J Intern Med, vol. 52, no. 1, pp. 84-89, 2020.

[2] D. Telaumbanua, "Urgensi Pembentukan Aturan Terkait Pencegahan Covid-19 di Indonesia," QALAMUNA J. Pendidikan, Sos. dan Agama, vol. 12, no. 01, pp. 59-70, 2020.

[3] Y. I. S. Setiawan, "Penetapan Karantina Wilayah Menurut Pandangan Legal Positivisme Dalam Rangka Pencegahan dan Pemberantasan Pandemi Coronavirus Disease (Covid)-19,” pp. 1-16, 2020.

[4] S. Komsiyah, "Model Petri Net Tak Berwaktu Pada Sistem Produksi (Batch Plant) Dan Simulasinya Dengan PIPE2," J. Mat Stat, vol. 12, no. 2, pp. 152-164, 2012.

[5] D. L. Rahakbauw, "Pemodelan Hybrid Sintesis Pada Automated Manufacturing System (AMS) Dengan Menggunakan Petri Net," J. Barekeng, vol. 6, no. 2, pp. 1-6, 2012. 
[6] D. Murdianto and D. Santoso, "Pemodelan Mesin Pengering Biji-Bijian Tipe Batch Menggunakan Hybrid Petri Net," Perbal J. Pertan. Berkelanjutan, vol. 7, no. 2, pp. 115-120, 2019.

[7] F. N. Wattimena, T. Pentury, and Y. A. Lesnussa, "Aplikasi Petri Net Pada Sistem Pembayaran Tagihan Listrik PT. PLN (Persero) Rayon Ambon Timur,” J. Barekeng, vol. 6, no. 1, pp. 23-30, 2012.

[8] R. K. Putri, “Aplikasi Petrinet Pada Sistem Identifikasi Sidik Jari,” J. Sains dan Inform., vol. 5, no. 2, pp. 148$156,2019$.

[9] R. I. Pertiwi and L. M Tridiana, "Model Petri Net Dari Antrian Klinik Kecantikan Serta Aplikasinya Pada Aljabar Maxplus," MAp (Mathematics Appl. J., vol. 2, no. 1, pp. 34-40, 2020.

[10] D. Mustofani and A. Afif, "Model Antrian Pelayanan Farmasi Menggunakan Petri Net dan Aljabar Max Plus," J. Mat. Pendidik. Mat., vol. 3, no. 1, pp. 33-43, 2018.

[11] S. A. Hardiyanti, I. Yuniwati, and A. D. Yustita, "Bentuk Petri Net Dan Model Aljabar Max Plus Pada Sistem Pelayanan Pasien Rawat Jalan Rumah Sakit Al Huda Genteng, Banyuwangi," J. UJMC (Unisda J. Math. Comput. Sci. ), vol. 3, no. 2, pp. 1-8, 2017.

[12] R. I. Pertiwi and F. Khasanah, "Aplikasi Petri Net Pada Sistem Pelayanan IGD RSUD Dr. Saiful Anwar Malang," J. Sci. Tech, vol. 5, no. 1, pp. 1-5, 2019.

[13] F. S. Tutupary and Y. A. Lesnussa, “Aplikasi Petri Net Pada Sistem Pelayanan Pasien Rawat Jalan Peserta Askes Di Rumah Sakit Umum Daerah Dr. Haulussy Ambon,” Gamatika, vol. III, no. 2, pp. 147-154, 2013.

[14] C. G. Cassandras and S. Lafortune, Discrete-Event Systems, Second. New York: Springer, 2008.

[15] Subiono, Aljabar Min-Max Plus dan Terapannya. Surabaya: Institut Teknologi Sepuluh Nopember, 2015. 